\title{
The Influence of Meteorology and Atmospheric Transport Patterns on the Sulfate Levels in Raiwater in Orizaba Valley, Veracruz, Mexico
}

\author{
Rosa María Cerón Bretón1, Jonathan Kahl2, Julia Griselda Cerón Bretón1, \\ José Angel Solís Canul ${ }^{1}$ \\ ${ }^{1}$ Chemistry Faculty, Autonomous University of Carmen, Ciudad del Carmen, Mexico \\ ${ }^{2}$ Department of Mathematical Sciences, University of Wisconsin-Milwaukee, Milwaukee, WI, USA \\ Email: rceron@pampano.unacar.mx
}

How to cite this paper: Bretón, R.M.C., Kahl, J., Bretón, J.G.C. and Canul, J.A.S. (2019) The Influence of Meteorology and Atmospheric Transport Patterns on the Sulfate Levels in Raiwater in Orizaba Valley, Veracruz, Mexico. Journal of Environmental Protection, 10, 821-837.

https://doi.org/10.4236/jep.2019.106049

Received: May 10, 2019

Accepted: June 21, 2019

Published: June 24, 2019

Copyright $\odot 2019$ by author(s) and Scientific Research Publishing Inc. This work is licensed under the Creative Commons Attribution International License (CC BY 4.0).

http://creativecommons.org/licenses/by/4.0/

(c) (i) Open Access

\begin{abstract}
This work assessed the relationship between synoptic circulation patterns, meteorological conditions and sulfate levels in rainwater in Orizaba Valley, Veracruz, Mexico during 2015. Samples were collected by using an automatic deposition sampler considering three climatic periods: Cold fronts or Nortes, Dry and Rainy seasons. Sulfate in rainwater was determined by turbidimetry (NMX-AA-SCFI-074-1981). A backward trajectory model (HYSPLIT) was used to characterize the potential source regions and transport pathways for air parcels arriving to Orizaba Valley; trajectories extended five days during 2015 were calculated. Mean concentrations of sulfate were 105.33, 37.5, and $52.5 \mu \mathrm{Eq} \cdot \mathrm{l}^{-1}$, for Cold Fronts, Dry and Rainy seasons, respectively. An evident dilution pattern was observed with lower concentration levels when rainfall increased. Mean values for sulfate concentration exceeded the background hemispheric value reported by Galloway et al. (1982) for remote sites (10 $\mu \mathrm{Eq} \cdot \mathrm{l}^{-1}$ ), exceeding almost $10,3.7$ and 5.2 times, during the Nortes, Rainy and Dry seasons, respectively. From the obtained results, it was concluded that the high sulfate levels in the rainwater measured in Orizaba Valley had their origin in different upwind regional sources as a result of long-range transport during Rainy and Nortes seasons.
\end{abstract}

\section{Keywords}

Atmospheric Transport, Rainwater, Sulfate

\section{Introduction}

Because of policies and regulations in matter of atmospheric pollution estab- 
lished in 90's decade by Environmental and Natural Resources Secretary in Mexico; atmospheric emissions of Sulphur compounds have decreased during the last years. However, some regions at the Southeast of Mexico could be under anthropogenic stress because of their location near industrial zones classified as critical, where natural ecosystems and big industrial facilities (gas and oil exploration, production and processing) coexist. The numerous industrial activities that take place along the coast of the Gulf of Mexico ("Sonda de Campeche") are of a great importance for the economy of the country; however, these activities also constitute a potential source of acid rain precursors [1]. In addition, besides of the contribution of local sources, sulfate levels observed in these sites could be improved because of the long-range transport from upwind distant sources during some climatic seasons. Mountain-Valley systems can be sensitive to Sulphur pollutants not only due to their complex topography, but also it has been reported that $\mathrm{S}$ deposition is major because of emissions released along the pathway of the backward trajectories passing over urban and industrial corridors located upwind, improving in a significant way the background levels of sulfate [2] [3].

Natural and anthropogenic pollutants are transported many hundreds of kilometers downwind from their sources before they were deposited on Earth's surface [4]. Pollutant levels in rainwater depend on the patterns and amount of emissions incorporating in the crossing air masses and meteorological conditions. Consequently, once aerosols and gases released to the atmosphere are transported over long distances, they are removed by dry or wet deposition [5]. In the case of wet deposition, it is the product of ion concentration and amount of precipitation over the sampling time; therefore, the input of pollutants is highly dependent of two main factors: 1) rainwater chemistry resulting from in-cloud and below-cloud atmospheric chemical reactions, and 2) meteorological parameters (type, frequency, duration of the event, rain amount, and wind direction) and air masses pathways that determine local/long-range transport of aerosols and their spatial distribution [6]. As a result of these synergic processes, some areas often experience high levels of air pollution associated with meteorological conditions that improve long-range transport from distant sources. Cerón et al. [7] have reported high sulfate levels measured with passive sampler (through fall samplers based on ionic exchange resin) for the region of Orizaba Valley. Therefore, the two major goals of this study were: 1) to characterize the long-range atmospheric transport to Orizaba Valley during 2015, and 2) to assess the relationship between synoptic circulation patterns, meteorological conditions and sulfate levels in the rainwater of Orizaba Valley, in Veracruz, Mexico.

\section{Study Area}

Climate in Orizaba Valley is sub-humid warm with rains occurring along the summer, with some transitional periods between seasons. The average annual 
rainfall is $2011 \mathrm{~mm}$, and the mean annual temperature is $19.5^{\circ} \mathrm{C}$ (Cerón et al., 2018).

Prevailing winds come from E-NE (at the end of November to March) when this site is under the influence of the cold fronts named "Nortes"; and from E-SE, during the rest of the year (from April to September), when the site is under the influence of tropical maritime air. In addition, there are some transitional periods in which meteorology can be complex (during October and at the beginning of November), when the site can be subjected to both, low pressure systems and cold fronts, resulting in stationary phenomena that contribute in a significant way to the annual total rainfall in the site.

Orizaba Valley is located at the mountainous region in the center of Veracruz State (Figure 1), with a high agriculture activity, multiple industrial sources and local emissions. In addition, Orizaba Valley is located downwind from three important zones in Mexico (Campeche, Tabasco and the Southeast region of Veracruz), where the main productive sector is petroleum (See Figure 1). Therefore, during rainy and cold fronts seasons, $\mathrm{SO}_{2}$ emissions are transported by air masses at a meso-scale level to be deposited as sulfate in Orizaba Valley.

\section{Methodology}

\subsection{Rainwater Sampling and Analysis of Sulfate}

Samples were collected in the roof of Chemistry Faculty of University of Veracruzin Orizaba City from January 1 to December 31 during 2015. For this study, three climatic periods were considered: Cold fronts (named also Nortes), Dry and Rainy seasons. Cold fronts season comprises from January to March, October, November and December. Dry season occur only during April and May, and Rainy season comprises from June to September.

Sampling was carried out by using an automatic wet/dry deposition sampler (Tisch, Inc.). Sampling device is equipped with a sliding cover which moves depending on the beginning or ending of the rain event, it has two buckets for the collection of dry and wet deposition. Rainwater samples were collected by the

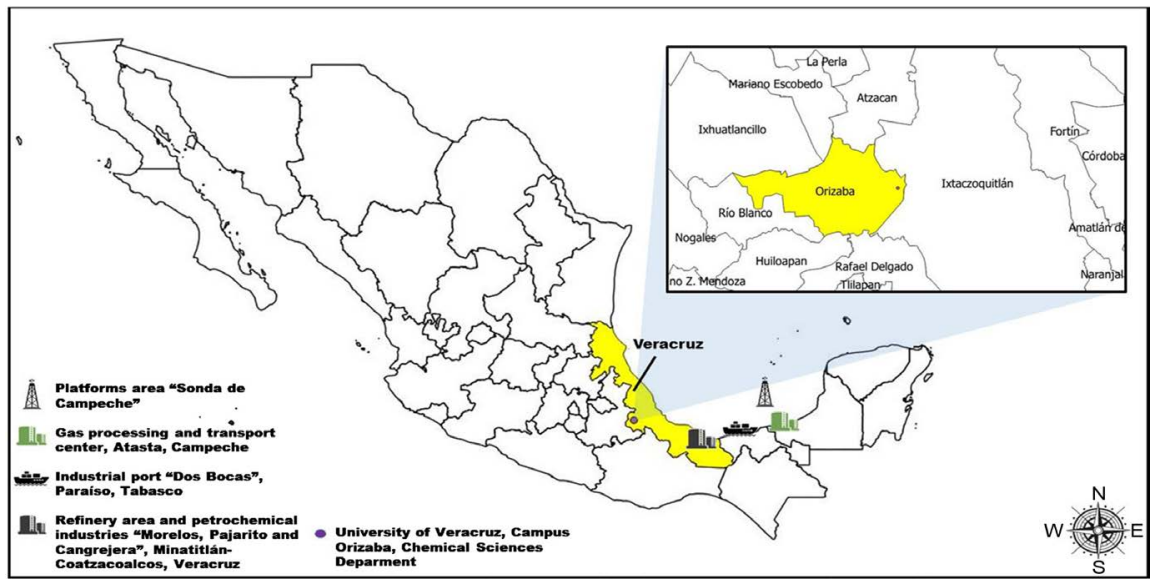

Figure 1. Map of the study region. 
automatic sampler in the wet mode. Trained technicians checked the samplers daily, typically at 8:00 h, local standard time, to retrieveand refrigerate any collected precipitation each day. Samples with a volume lesser than $250 \mathrm{ml}$ or with a visible pollution were discarded. The amount of rain associated was registered by a rain gauge. Samples were sent to Environmental Sciences Laboratory at Autonomous University of Carmen, where they were filtered (with a Kontes ${ }^{\circledast}$ Ul-

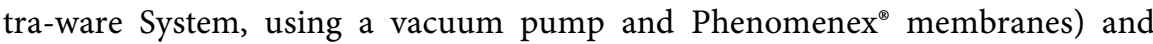
analyzed for $\mathrm{SO}_{4}^{2-}$. Sulfate was determined by turbidimetry [8].

\subsection{Meteorology and Air Mass Pathways}

The backward trajectory model (HYSPLIT) was used to characterize the potential source regions and transport pathways for air parcels arriving to Orizaba Valley, trajectories extended five days for the period from January 1 to December 31, during 2015, were calculated.

\section{Results}

\subsection{Rainwater Chemistry}

Figure 2 shows mean, maximum and minimum values for sulfate concentrations by sampling season. Sulfate levels in the rainwater collected in Orizaba Valley during 2015 showed an evident seasonal pattern with the following relative abundance: Cold fronts (Nortes) $>$ Rainy $>$ Dry. There was an evident dilution pattern with lower values when rainfall increased, however, also during the dry season, lower levels observed could be a result of a shift in the prevailing wind direction.

During the Cold fronts season a total of62 rain events occur along six months, sulfate levels ranged from 38 to $131 \mu \mathrm{Eq} \cdot \mathrm{l}^{-1}$, with a mean value of 105.33 ; whereas during the Dry season, a total of 11 rain events occur along two months, sulfate levels ranged from 18 to $74 \mu \mathrm{Eq} \cdot \mathrm{l}^{-1}$, with a mean value of 37.5 . The mean value of

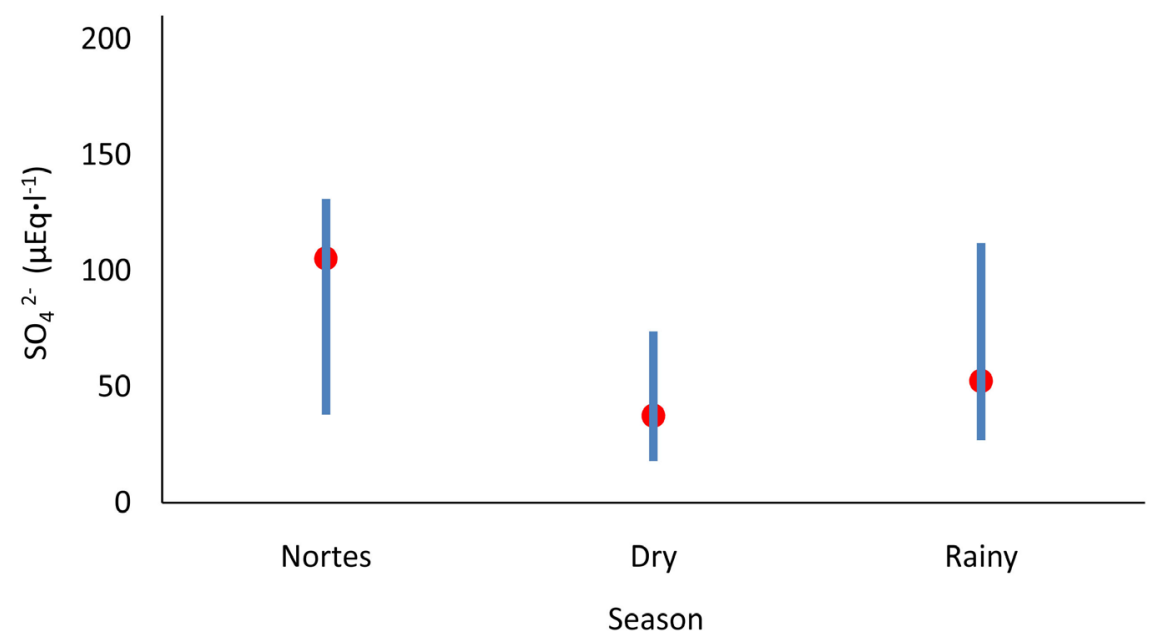

Figure 2. Mean Sulfate concentrations in the rainwater collected by season in Orizaba Valley during 2015. 
sulfate during the Rainy season was $52.5 \mu \mathrm{Eq} \cdot \mathrm{l}^{-1}$, with a maximum of 112 and a minimum of $27 \mu \mathrm{Eq} \cdot 1^{-1}$, respectively; a total of 77 rain events occur along four months. In all seasons of 2015 the mean values for sulfate concentration exceeded the background hemispheric value reported by Galloway et al. [9] for remote sites $\left(10 \mu \mathrm{Eq} \cdot 1^{-1}\right)$. The highest mean sulfate level was found during the Cold fronts season (Nortes) (105.33 $\mu \mathrm{Eq} \cdot \mathrm{l}^{-1}$ ) exceeding almost ten times the background hemispheric values reported by Galloway et al. [9]; whereas during the Rainy and Dry season, the exceedances were 3.7 and 5.2, respectively.

According to Ponette-Gonzalez et al. [10], in some places of Central Veracruz, there is an acidification risk since the high lands are located downwind of the most important industrialized regions in Mexico, where facilities that release significant quantities of Sulphur (power plants, extraction and production of gas and oil, refineries, petrochemical complexes, paper and sugar industry) coexist. The findings of Ponette-Gonzalez et al. [10] are according to those reported by Parungo et al. [11], who reported that anthropogenic sources located upwind increase $S$ deposition in the mountain ecosystems of Sierra Madre Oriental in Central Veracruz.

Cerón et al. [12] reported sulfate levels for Atasta and Ciudad del Carmen in Campeche state lower than levels presented in this study. It is important to mention that Ciudad del Carmen is located upwind Atasta, and Atasta is located upwind Orizaba Valley; and both sites are located at the East from Orizaba Valley and just near the most important emission sources in Campeche state (Figure 1). Since $\mathrm{SO}_{2}$ is a regional pollutant, it is not deposited in the surroundings of its emission point. Its spatial and temporal variability, and its residence time in the atmosphere determine that it be deposited as sulfate at sites downwind and relatively distant from its emission point. Cerón et al. [7] report that as sites are located at the west of Campeche Gulf ("Sonda de Campeche"), S levels trend to increase. Residence time of $\mathrm{SO}_{2}$ in the atmosphere is approximately 2 - 5 days, enough time for air masses travel (crossing the southeastern and northeastern side of the country, and even from the southern of United States and Canada) with a compound of west-southwest (during rainy and cold fronts seasons). Along this trajectory, $\mathrm{SO}_{2}$ is transformed and deposited as sulfate, and these concentration values are higher in direction west and southwest.

Sosa et al. [13] studied the interannual variability of the chemical composition (ions and $\mathrm{pH}$ ) of the rainwater in La Mancha, Veracruz from 2003 to 2014 in a daily basis. La Mancha is a site located at the coast of the Gulf of Mexico in the center of Veracruz at approximately $150 \mathrm{~km}$ at Northeast of Orizaba Valley. Sosa et al. [13] only considered two seasons for their study, dry and rainy season, and cold fronts season was not considered in their discussion. They reported sulfate levels ranging from 16 to $32 \mu \mathrm{Eq} \cdot \mathrm{l}^{-1}$, and $\mathrm{pH}$ from 4.78 to 5.40 with a mean value of 5.22. It was not possible to compare sulfate levels found by Sosa et al. (2018) during cold fronts season with the results of this study, because of, they grouping typical cold fronts months (November, December, January, February and March) and typical dry months (April and May) as Dry season. In the case of 
this study, we separate the different months along of the year in three seasons, since, cold fronts or Nortes season is an important climatological phenomenon in Veracruz state that it is worth being discussed separately. However, in the case of the Rainy season, it was possible to establish a comparison with data obtained by Sosa et al. [13]. Mean sulfate concentration during the rainy season for this study was $37.5 \mu \mathrm{Eq} \cdot \mathrm{l}^{-1}$, this value is close to those values reported by Sosa et al. (2018) for La Mancha (16 to $32 \mu \mathrm{Eq} \cdot \mathrm{l}^{-1}$ ).

However, it is necessary to consider that chemical of the rainwater is a function of the amount of precipitation and can vary from year to year, and from location to location.

\subsubsection{Dilution Effect of Rainwater on Chemistry Composition}

The observed sulfate concentrations showed a decreasing trend as precipitation amount increases (Figure 3); it suggests that rainwater had a dilution effect on precipitation chemistry. Precipitation chemistry may also be partially dependent on the residence time of floating particles in the air [14].

During the Cold fronts or Nortes season, the highest sulfate levels were found during January and December, whereas during the Dry season, the lowest sulfate levels occurred along May. The dilution effect was completely evident during July and September, since they showed the highest rain amounts and the lowest sulfate levels. From Figure 3, it is possible to observe the bimodal distribution in rain amount, with two maximum values at July and September, and a relative minimum value during August known as mid-summer drought. This phenomenon has been observed in other areas at the Southeast of Mexico [15], and could explain why sulfate levels were relatively higher during August in comparison with July and September.

\subsubsection{Seasonality, Sulfate Levels and $\mathrm{pH}$}

Focusing on sulfate deposition during 2015, sulfate levels in rainwater ranged from 18 to $131 \mu \mathrm{Eq} \cdot \mathrm{l}^{-1}$, with a mean value of $65.11 \mu \mathrm{Eq} \cdot \mathrm{l}^{-1}$. The highest concentrations of sulfate in rainwater of Orizaba Valley were observed mainly during Cold Fronts and Rainy season. However, applying Mann-Whitney test (at significance level of

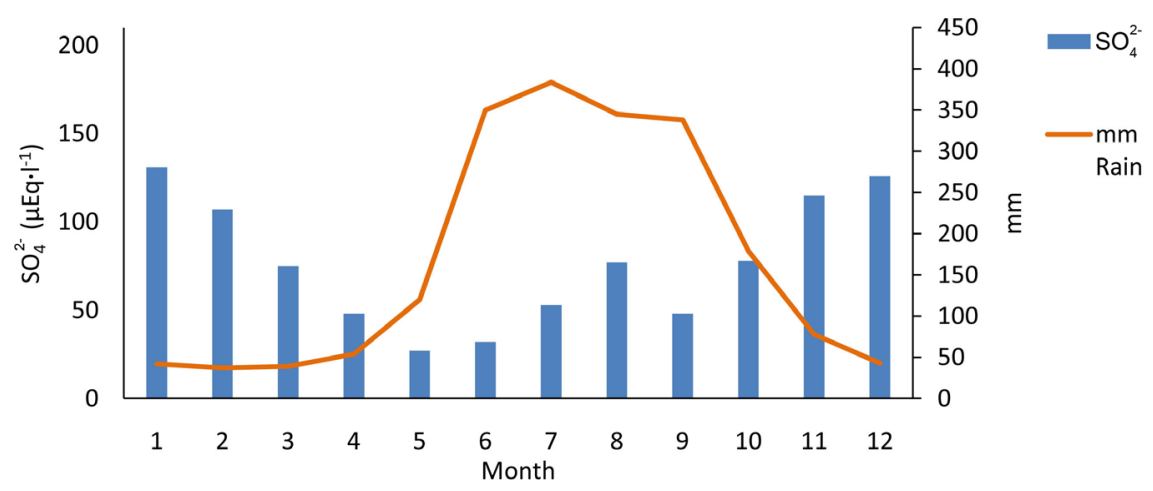

Figure 3. Dilution effect on sulfate concentration in the rainwater collected during 2015 in Orizaba Valley, Veracruz, Mexico. 
0.05), sulfate levels showed significant differences between these seasons, attributed to the origin of the air masses and as a result of the prevailing circulation.

Sulfate levels in rainwater were analyzed considering Cold fronts season, Dry season (this season take place between Cold fronts and Rainy season), and Rainy season. For countries with a monsoon climate as the case of Mexico, the amount of rain depends on the month of the year and can vary from year to year (See Figure 4).

From Figure 4, it can be observed that the lowest rain amount occurred in February with a mean of $37 \mathrm{~mm}$, whereas, the highest amount was observed during July with a mean of $384 \mathrm{~mm}$. As can be observed from Figure 4, the amount of rain showed a seasonal variability, with the highest amounts of precipitation during the Rainy season in comparison with Cold fronts season and the rest of the year. In addition, it can be observed that the amount of rain varies significantly between Cold fronts and Rainy season. It is important to note that during Cold fronts season, great number of precipitation events had a small volume in comparison with events occurring during the Rainy season.

As a result, a dilution effect [16] can be expected during the Rainy season (characterized by intense and heavy rains). It could explain why sulfate levels in rainwater were lower during the Rainy season in comparison with Cold front season.

$\mathrm{pH}$ ranged from 3.56 to 6.4 , with a mean value of 5.18. $\mathrm{pH}$ mean value is according to that reported by Sosa et al. [13] in La Mancha, Veracruz (5.22). Figure 5 shows that $\mathrm{pH}$ values were higher during May and June, when sulfate levels were lower; whereas, $\mathrm{pH}$ values were lower during January and December, when sulfate levels in rainwater were higher. It could be explained not only from the dilution effect, since it is well known that rain amounts during Cold fronts are significantly lower than during the summer (Rainy season), but also from the path of air masses trajectories.

\subsection{Relationship between Meteorology, Synoptic Circulation Patterns and Sulfate Levels}

To better characterize dominant meteorological influences and air masses

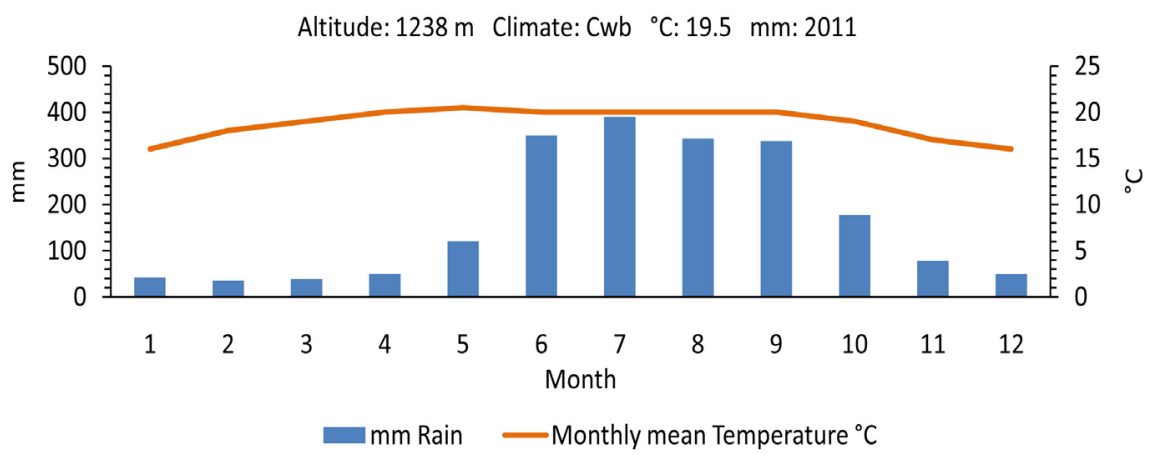

Figure 4. Climatic table for Orizaba Valley during 2015 (Red line is trend line in mean temperature along the year). 


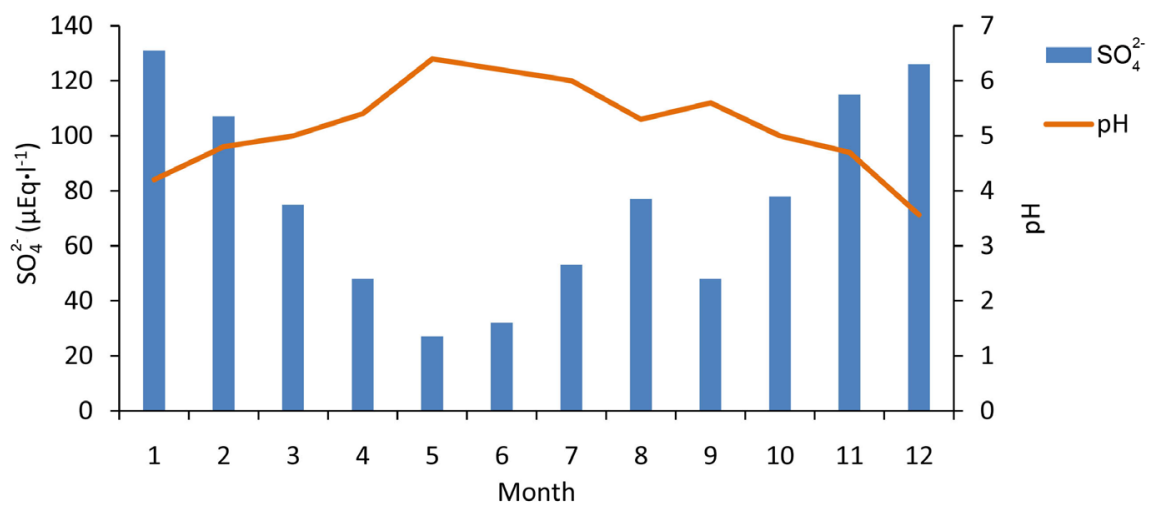

Figure 5. Monthly mean sulfate concentration and $\mathrm{pH}$ values for the rainwater collected in Orizaba Valley during 2015.

pathways, sulfate levels in rainwater were analyzed considering both classification, trajectories associated to Cold Fronts and trajectories associated to Tropical Maritime Air.

In Figure 6, it can be observed that during Cold fronts season the prevailing wind direction was North, whereas during Dry and Rainy seasons, the dominant wind direction was East. It could explain the differences in sulfate levels observed between both humid seasons. During Cold fronts or Nortes season, the long-range transport is improved, resulting in high sulfate levels.

On the other hand, during Rainy season, specially along July, prevailing wind direction is from East, with high wind speeds that promote the transport of air masses not only from Caribbean Sea but also the transport of pollutants from gas and oil offshore platforms in "Sonda de Campeche". However, because of the dilution effect associated to the high rain amounts during this season, the sulfate levels found were relatively lower in comparison with Cold fronts season. It is important to mention that, during transitional periods, wind direction can have a combination in its components, as the case of February, March and October, when, a combination of the components was significantly higher in comparison with the remaining months of the year. From Figure 6, it can be observed that, other wind directions different from North and East can occur, being more significant during Cold fronts or Nortes season.

\subsubsection{Long-Range Transport}

Five-day long back-trajectories for three different altitudes (500, 1500 and 3000 m) calculated with HYSPLIT model [17] were used to study the influence of different air masses on sulfate levels in the rainwater collected in Orizaba Valley during 2015 (Figure 7). The rainwater events were classified in: Tropical Maritime Air and Cold Fronts or Nortes.

Kahl et al. [18] reported two main patterns for El Tajin, a near region located at $300 \mathrm{~km}$ at Northeast of Orizaba Valley in the State of Veracruz. Our findings in this study are in agreement with those reported by [18]. The first one, an easterly flow associated with the southern portion of the subtropical high. This easterly flow dominates the transport along the summer season, when all trajectories pass 


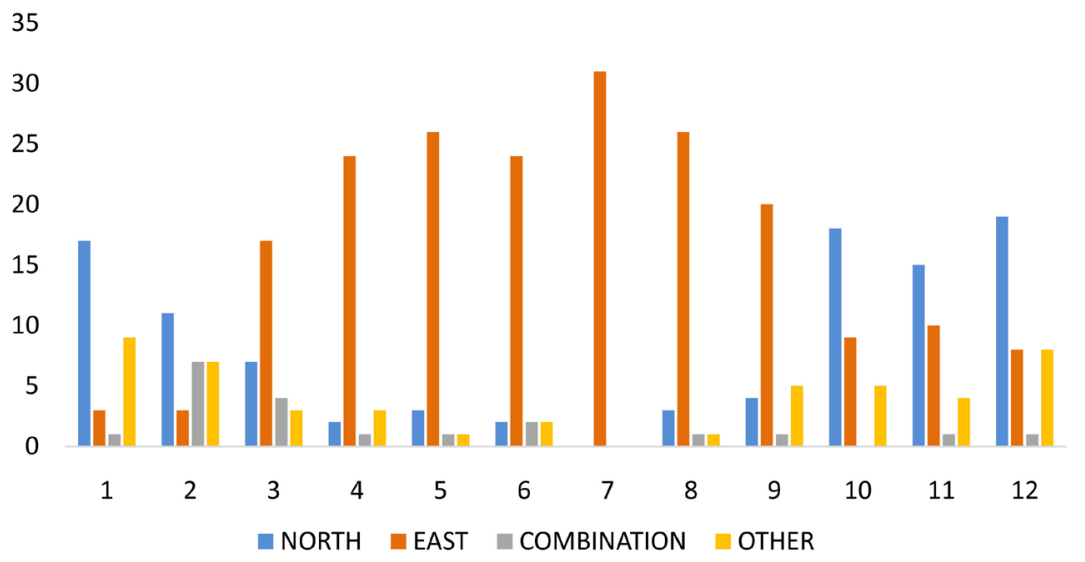

Figure 6. Prevailing wind direction by month during 2015 in Orizaba Valley, Veracruz, Mexico.

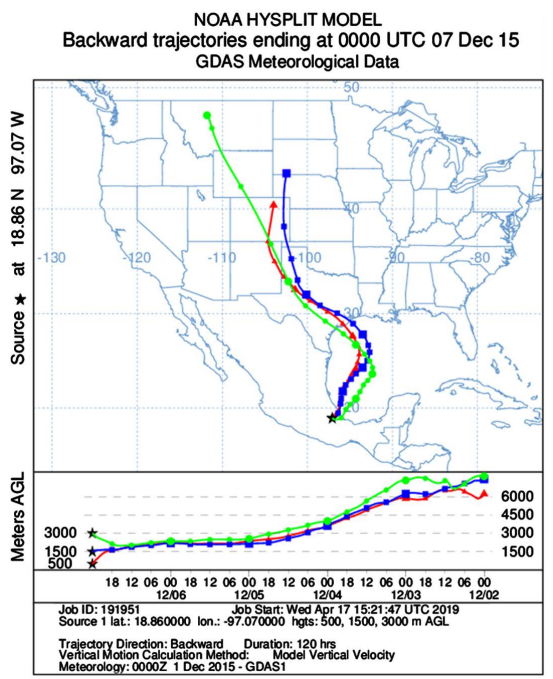

(a)

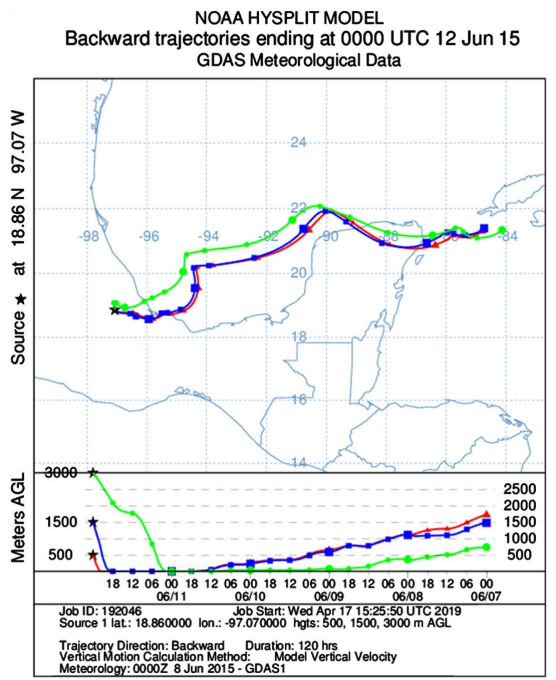

(c)

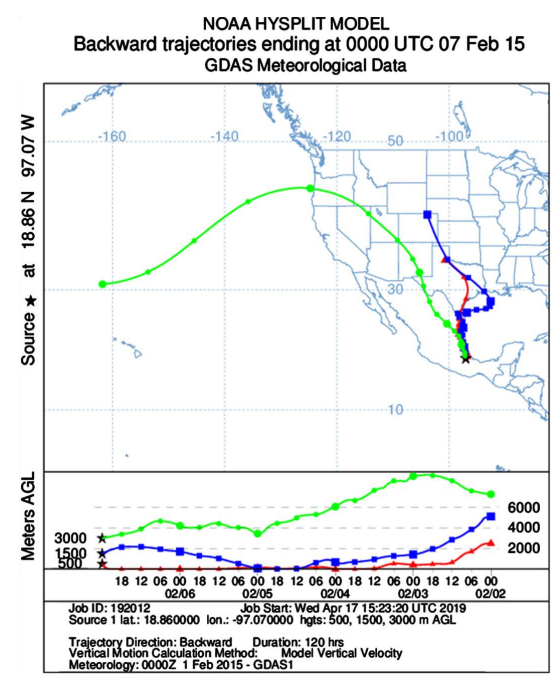

(b)

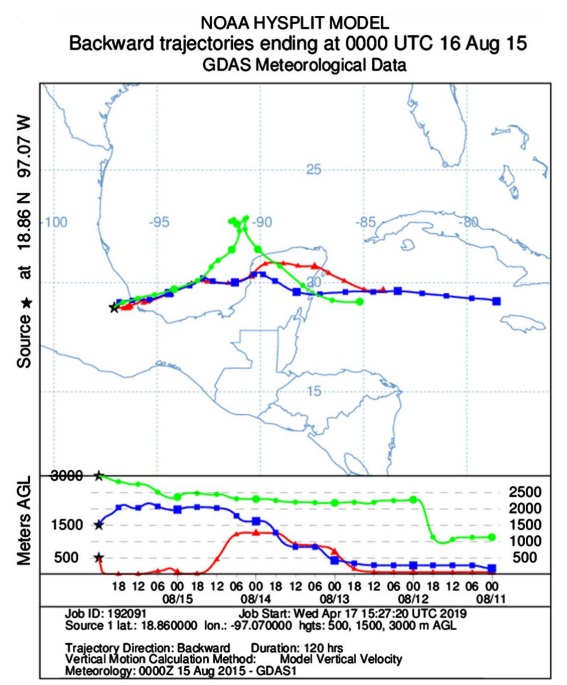

(d)

Figure 7. Five days back-trajectories for the different rainwater events: ((a), (b)) Cold Fronts or Nortes; ((c), (d)) Tropical Maritime Air. 
over the Caribbean Sea and "Sonda de Campeche" (where facilities for exploration and production of oil and gas are located) before arriving to Orizaba Valley (Figure 7). Wind speeds are strongest during the summer (Figure 8), and rain events during this season are associated to cyclonic flows (tropical waves, tropical storms and hurricans), in which low pressures were observed (Figure 9). The second one, the North to Northwesterly flow is an important influence during the winter season (Cold fronts or Nortes season) with five-day trajectories coming from the South and Southeastern of the United States of America. During these months, trajectories pass over the Northeast side of Mexico and some states at the Southern of United States. Rain events during this season are associated to anticyclonic circulation characterized by high pressure disturbance (Figure 9), wind speeds (Figure 8) and rain amount by event (Rain in $\mathrm{mm}$ ) relatively lower in comparison with the summer season.

From Figure 8, circulation patterns at the selected time periods were examined to determine the association between meteorological conditions and the dominant air mass type. As mentioned above, the trajectories showed two different meteorological regimes that control the transport to Orizaba Valley in two

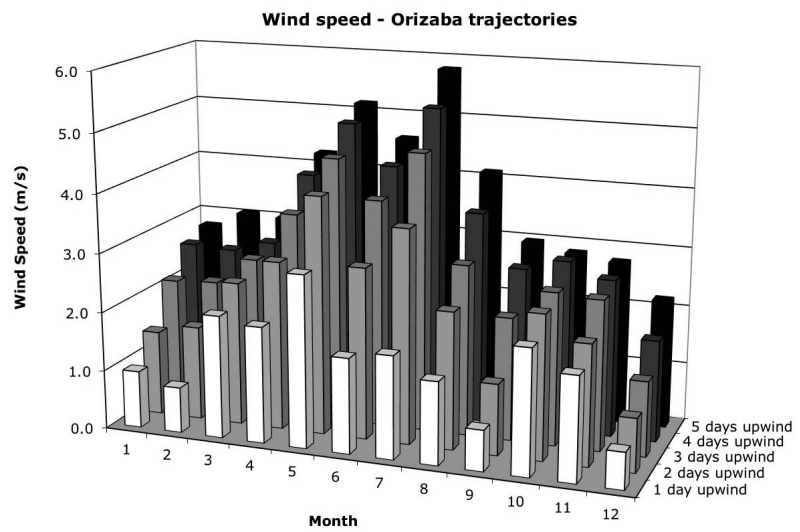

Figure 8. The mean wind speed of air parcels in route to Orizaba Valley as a function of the month of arrival and distance from Orizaba Valley during 2015.

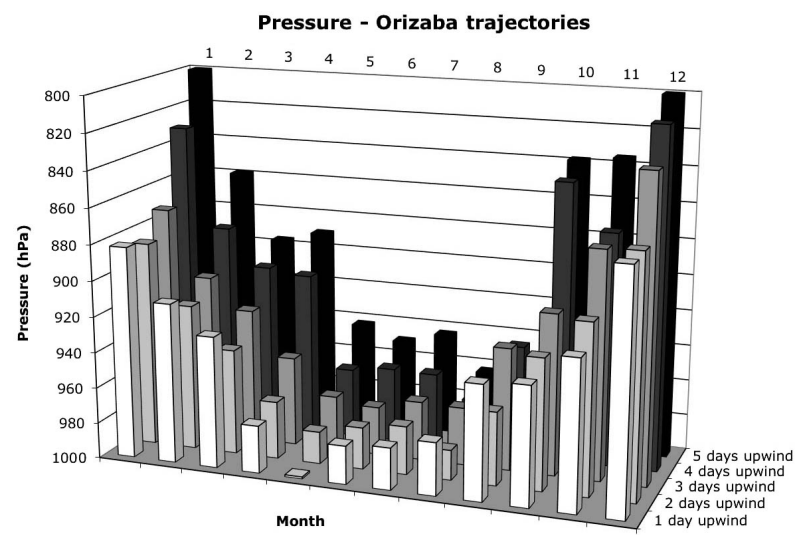

Figure 9. The mean vertical position of air parcels in route to Orizaba Valley as a function of the month of arrival and distance from Orizaba Valley. The vertical scale of atmospheric pressure corresponds to altitudes of 0 - $2000 \mathrm{~m} \cdot \mathrm{asl}$. 
different climatic periods of the year. The first one, the easterly flow dominates the transport during the Rainy season, when all trajectories pass over the Caribbean Sea, crossing the Yucatan Peninsula and the Gulf of Mexico before arriving to Orizaba Valley, when wind speeds are strongest.

The second one, the north-northeasterly flow associated with the North American anticyclone controls the transport during the Cold Fronts season, with five-day trajectories extending as far back as Canada; Central, Southern and Southeastern of United States; with trajectories passing over Texas, Nuevo Mexico, Arizona and Northern of the Gulf of Mexico.

In Figure 9, the mean vertical position of air parcels in route to Orizaba Valley as a function of month of arrival and distance from Orizaba Valley is presented. The vertical scale of atmospheric pressure corresponds to altitudes of 0 $2000 \mathrm{~m} \cdot$ asl. The mean vertical position of air parcels shows that from June to August (Rainy season) when the direction of multi-day transport is almost exclusively from Easterly, air remains at low altitudes (altitudes $\leq 200 \mathrm{~m}$, with pressures between 910 to $980 \mathrm{hPa}$ ).

During the air transport at these low altitudes, it is probably that regional sources located upwind contribute significantly to the sulfate concentrations at receptor level. In the case of Orizaba Valley, sources located upwind are platforms offshore for the exploration and production of oil and gas in "Sonda de Campeche"; sour gas processing facilities located in Atasta and Dos Bocas Port; and petrochemical industries located along the industrial corridors Minatitlan-Coatzacoalcos and Morelos-Pajarito-Cangrejera.

According to the last National inventory of emissions in Mexico (sinea.semarnat.gob.mx/sinea.php), $\mathrm{SO}_{2}$ (Ton $\mathrm{yr}^{-1}$ ) emissions were 576,247.83, 15,104.43 and 167,448.54, for Campeche, Tabasco and Veracruz. These three states together contribute with $33.85 \%$ of total emissions of $\mathrm{SO}_{2}$ in the country, and Campeche state contributes with $25.71 \%$. The industrial corridors Minatitlan-Coatzacoalcos and Morelos-Pajarito-Cangrejera are located at the East-Southeast from Orizaba Valley, where oil refineries, chemical and petrochemical facilities are located. In addition, in Tabasco state, there are several terrestrial petroleum facilities (exploration, production, maritime terminals, storage terminals, and gas processing plants). Additionally, in Campeche state, gas and oil exploration and production offshore facilities are in "Sonda de Campeche", including a sour gas recompression plant in Atasta. Since, all these sources are located upwind Orizaba Valley, under the influence of some meteorological conditions, sulfate levels in this region could be improved because of long-range transport.

According to Figure 9, from January to March (the second half of cold fronts or Nortes season), when the direction of multi-day transport is from Northeasterly, air parcels located at 1 and 5 days upwind Orizaba Valley tend to remain at altitudes between 800 and $1600 \mathrm{~m}$; whereas from October to December (the first half of cold fronts or Nortes season), air remains between 400 and $1600 \mathrm{~m}$ of altitude. Trajectories altitudes during Nortes season were considerably higher in 
comparison with Rainy season. Despite the greater potential for dilution over large air volumes, it can be observed that the contribution from upwind sources was significant during this season. Industrial sources in places located upwind from Orizaba Valley could contribute to the highest sulfate concentrations observed in the rainwater collected in Orizaba, some of these places were Canada; Southern Texas, Arizona, Nuevo Mexico, Kansas, Oklahoma, Northeastern shoreline in the Gulf of Mexico in United States; and Coahuila, Nuevo León and Tamaulipas states in Mexico.

From 5-day backward trajectories, Kahl et al. [18] established two main meteorological controlling the transport to the Northern of Veracruz state. The first one, an easterly Flow during the summer season (from June to August), when trajectories of air masses pass over Caribbean Sea, crossing Yucatan Peninsula and the Southern of the Gulf of Mexico (Gulf of Campeche, where offshore platforms are located). The second one, a North-Northwesterly Flow associated to anticyclonic circulation of North America, that influences during the winter season (cold fronts), improving the transport from Central and Southern of United States, with air mass trajectories passing over Texas, the Northern of Gulf of Mexico (where also offshore platforms are located) and the North side of Mexico.

Results found in this study are according to those reported by [18], who demonstrated the long-range transport from two main directions at the Northern side of Veracruz (El Tajin), identifying the offshore petroleum fields at the Southern of the Gulf of Mexico, and petroleum facilities in Atasta and Dos Bocas in Campeche and Tabasco states as the main sources during the summer season. In the other hand, during the cold front season, air masses were transported from the North of the country, therefore, sources located at this direction could contribute to sulfate levels in Orizaba Valley, in this case, identified sources besides Altamira in Tamaulipas and Poza Rica in Veracruz (where power plants and petroleum facilities are located) were Tampico and Matamoros in Tamaulipas, Monterrey in Nuevo León and Brownsville in Texas.

\subsubsection{Long-Range Transport Corresponding to the Highest Sulfate} Levels in the Rainwater Measured in Orizaba Valley

Table 1 shows the dates in which the highest sulfate levels were identified and

Table 1. Dates with the highest sulfate levels during 2015 and wind directions associated.

\begin{tabular}{ccc}
\hline Date & Wind Direction & Sulfate concentracion $\left(\mu \mathrm{Eq} \cdot \mathrm{l}^{-1}\right)$ \\
\hline January 1 & N: Cold Front Event & 131 \\
October 20 & N-NE: Cold Front Event & 127 \\
December 5 & N-NW: Cold Front Event & 119 \\
August 7 & E-NE: Tropical Wave Event & 86 \\
August 21 & E-SE: Hurrican Danny & 112 \\
August 31 & E-NE: Tropical Wave Event & 99
\end{tabular}


the wind direction associated to each rain event; it can be observed that the highest sulfate level was found in rainwater collected during January 1 when a Cold front event occurred. However, during August, there were rain events associated to hurricane activity in the Caribbean Sea (Hurricane Danny) that promote the transport of air masses and pollutants from "Sonda de Campeche", resulting in relatively high sulfate levels.

To assess the possible relationship between air transport pathways and the sulfate levels in the rainwater collected in Orizaba Valley during 2015, trajectories for those events of rainwater which exhibited the highest sulfate concentrations in rainwater samples were calculated (Figure 10). As would be expected from the long-range transport, the trajectories for the most of events analyzed depicted air transport from north-northeasterly or east-southeasterly directions. A clear relationship between high sulfate levels observed and trajectory path was found.

From Figure 10(a), it can be observed that trajectories at 500, 1500 and 3000 $\mathrm{m}$ of altitude came from Caribbean Sea passing by Belize, Guatemala and the Southern of Yucatan Peninsula. However, at 1500 and $3000 \mathrm{~m}$, the trajectories in their final path pass by the shoreline of Campeche, Tabasco and Veracruz states, precisely where some facilities for petroleum processing are located (oil refineries, petrochemicals, and so on); whereas at $500 \mathrm{~m}$, air masses cross "Sonda de Campeche", where platforms for oil and gas exploration and production are located.

In Figure 10(b), at $3000 \mathrm{~m}$, air masses came from the Caribbean Sea (at these dates, the hurricane Danny had been formed in the Caribbean region) crossing Guatemala, Chiapas and the Gulf of Mexico. At $1500 \mathrm{~m}$, the trajectories came from Central America passing by the shoreline of Guatemala and crossing Chiapas and Tabasco states. Finally, at $500 \mathrm{~m}$, air masses came from the Southern of Yucatan Peninsula passing by "Sonda de Campeche" (the most important region in Mexico for the exploration and production of gas and oil).

At 1500 and $3000 \mathrm{~m}$ (Figure 10(c)), the air masses travel from Caribbean Sea passing by the Southern of Yucatan Peninsula. At $3000 \mathrm{~m}$, the final path passes through the shoreline of Tabasco and Veracruz states (where some facilities for petroleum processing are located as oil refineries and petrochemicals); whereas at $1500 \mathrm{~m}$ pass through "Sonda de Campeche" (offshore gas and oil production region in Mexico). On the other hand, at $500 \mathrm{~m}$, air masses were crossing the Gulf of Mexico passing by "Sonda de Campeche" (offshore gas and oil processing region).

In Figure 10(d), it can be observed that in comparison with the Rainy season, during the Cold fronts or Nortes season, trajectories became more complex. At $500 \mathrm{~m}$ of altitude, trajectories were traveling from Pacific Ocean passing by some states in United States of America as California, Nevada, Arizona, Nuevo Mexico and the Southern of Texas, with their final path through Northeastern coast of the Gulf of Mexico before to arrive to Orizaba Valley. At $1500 \mathrm{~m}$ of altitude, air masses came from Canada crossing by United States of America (Montana, 


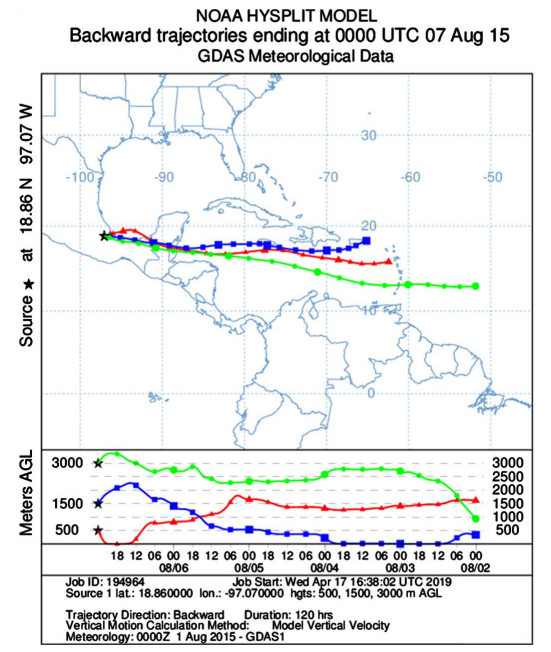

(a)

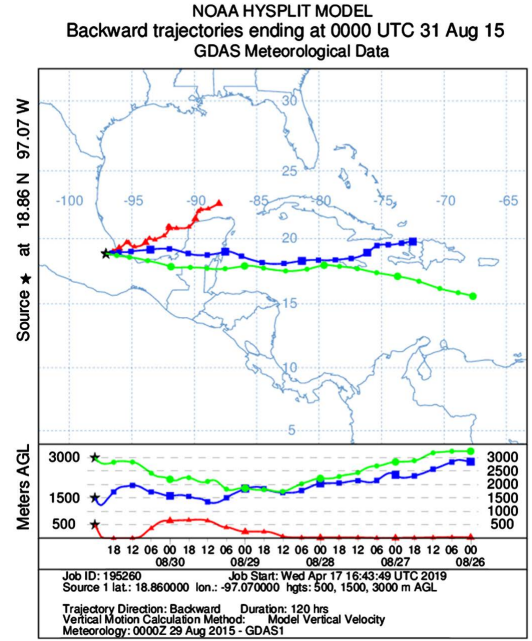

(c)

NOAA HYSPLIT MODEL Backward trajectories ending at 0000 UTC 01 Jan 15 GDAS Meteorological Data

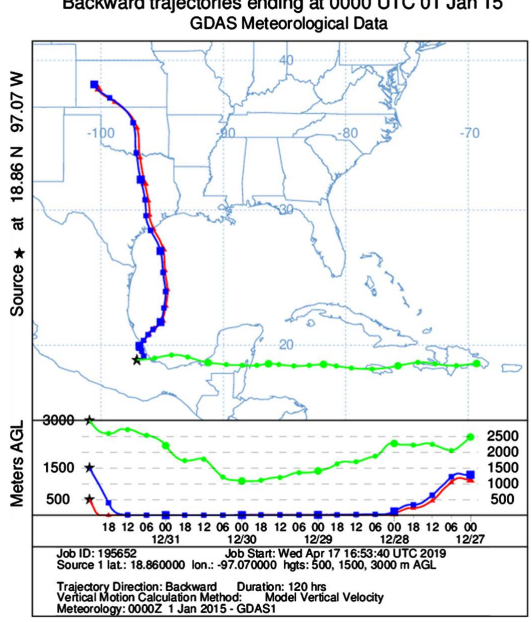

(e)

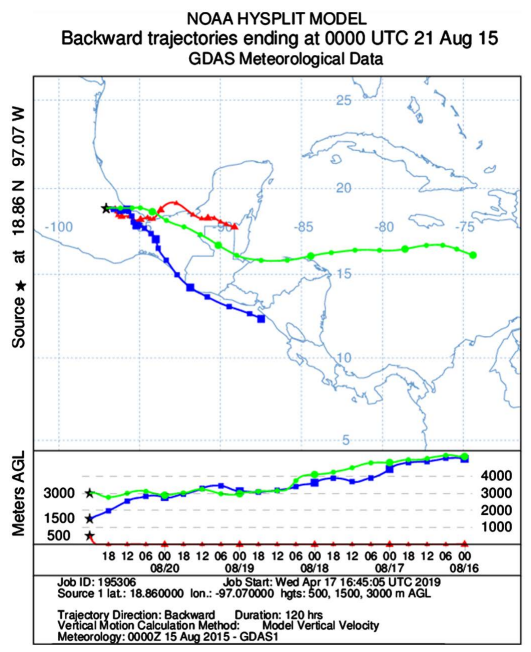

(b)

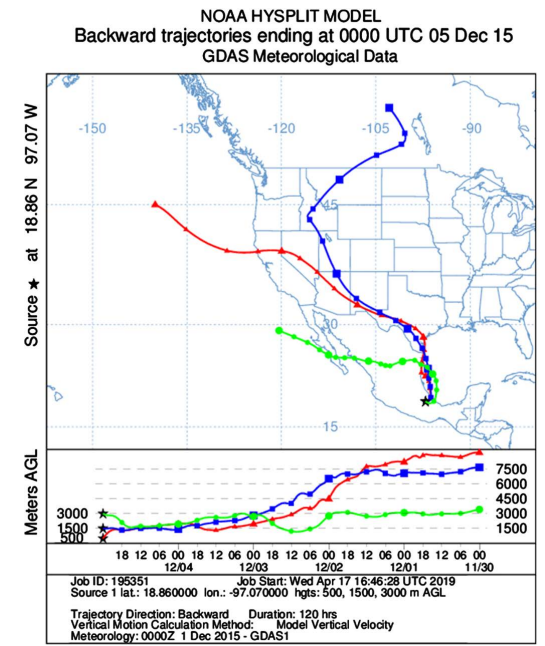

(d)

NOAA HYSPLIT MODEL Backward trajectories ending at 0000 UTC 20 Oct 15 GDAS Meteorological Data

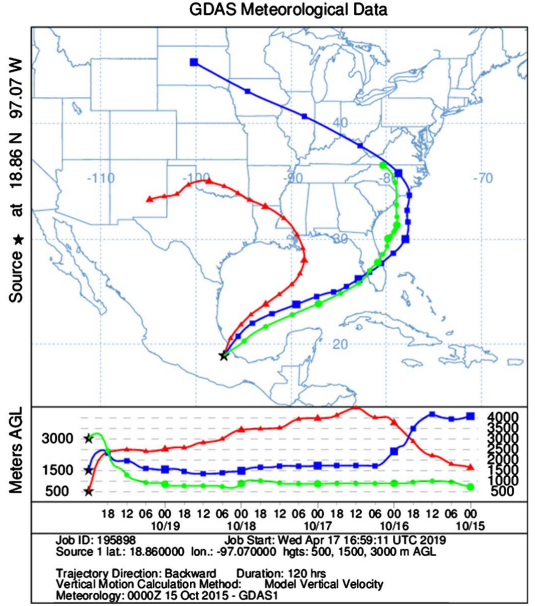

(f)

Figure 10. Five day trajectories corresponding to four precipitation events with the highest sulfate concentrations at Orizaba Valley for ((a), (b), (c)) Tropical maritime Air event; ((d), (e), (f)) Cold Fronts or Norte event. 
Idaho, Utah, Arizona, Nuevo Mexico and the Southern of Texas) and finally passing through Northern shoreline of the Gulf of Mexico, before to arrive to the center of Veracruz state. Finally, at $3000 \mathrm{~m}$, trajectories have a different behavior, coming from the Pacific Ocean, crossing the Baja California Peninsula and the states of Sinaloa, Durango, Coahuila, Nuevo León and Tamaulipas, also passing through the Northern of Gulf of Mexico before to arrive to Orizaba Valley.

According to Figure 10(e), at 500 and $1500 \mathrm{~m}$, trajectories are very similar, coming from Kansas, crossing Oklahoma and Texas, with the final path through Northwest side of the Gulf of Mexico. At $3000 \mathrm{~m}$, the behavior of the air masses trajectory is very different, coming from the Caribbean Sea, crossing Yucatan Peninsula and passing through "Sonda de Campeche" (Area for processing of gas and oil in offshore petroleum platforms).

In Figure 10(f), it can be observed that, at $500 \mathrm{~m}$ of altitude, air masses came from Nuevo Mexico, passing through the Northern of Texas, the Southern of Oklahoma, the Northern of Louisiana, and the offshore platforms area in the Northern of the Gulf of Mexico, and finally crossing "Sonda de Campeche" (where gas and oil offshore platforms are located). At $1500 \mathrm{~m}$, trajectories came from South Dakota, traveling to Iowa, the Northern of Illinois, Indiana, Ohio, the Northern of Kentucky, the Southern of West Virginia, Virginia and North Carolina, crossing Florida and "Sonda de Campeche" (gas and oil exploration and production area in offshore platforms). Finally, at $3000 \mathrm{~m}, 5$-day air masses came from North Carolina, crossing through Florida, with a final path through "Sonda de Campeche" (area for processing of gas and oil in the Southern of the Gulf of Mexico).

\section{Conclusions}

Sulfate levels during the Cold fronts season showed a maximum value of 131 $\mu \mathrm{Eq} \cdot \mathrm{l}^{-1}$, and a mean value of $105.33 \mu \mathrm{Eq} \cdot \mathrm{l}^{-1}$. The dominant circulation patterns found during winter season and the dilution effect because of the heavy rains during the Rainy season, could explain these high levels, since Orizaba Valley was under the influence of northeastern flow or cold fronts season named also Nortes from January to March, and from October to December. Sulfate levels during the rainy season showed a maximum value of $74 \mu \mathrm{Eq} \cdot \mathrm{l}^{-1}$, and a mean value of $37.5 \mu \mathrm{Eq} \cdot 1^{-1}$; these values are close to those reported by Sosa et al. (2018) during the Rainy season in a site located at $150 \mathrm{~km}$ at Northeast from Orizaba Valley.

Findings of this study were similar than those reported by Kahl et al. [18]. From June to August, when multi-day transport direction (5 days) is from East, air remains at low altitudes $(200 \mathrm{~m} \cdot \mathrm{asl})$. At these conditions, the relative contribution from regional sources could be significant, considering that the distance in straight line between Orizaba Valley and offshore platforms in "Sonda de Campeche" is approximately $450 \mathrm{~km}$ at East. Estimated transport from offshore platforms in "Sonda de Campeche" to Orizaba Valley as a function of wind di- 
rection is from 1 to 5 days. Therefore, observed flows in both, this work and [18] probably influence on the transport of air masses arriving to Orizaba Valley during the Rainy and Cold fronts seasons.

It can be concluded that sulfate levels observed in the rainwater samples collected in Orizaba Valley during 2015 were originated in regional sources, whose contribution was higher when Orizaba Valley was under the influence of trade winds (Maritime Tropical Air) during the Rainy season, and North winds (Nortes) during the Cold Fronts season.

There was an evident increase in the background sulfate levels as a result of the long-range transport of regional emissions of $\mathrm{SO}_{2}$ released in distant sources locate upwind Orizaba Valley. $\mathrm{SO}_{2}$ emissions released in offshore platforms in "Sonda de Campeche" and industrial sources in the Northern of Mexico and in the Southern of United States influenced in a significant way on S deposition in the Mountainous Region of Central Veracruz. The exceedances in reference values (background hemispheric levels for remote sites) indicate the potential risk of acidification and the vulnerability of the ecosystems in this region.

\section{Conflicts of Interest}

The authors declare no conflicts of interest regarding the publication of this paper.

\section{References}

[1] Hutchinson, T.C. and Havas, M. (2012) Effects of Acid Precipitation on Terrestrial Ecosystems. Springer, Berlin, 654 p. https://doi.org/10.1007/978-1-4613-3033-2

[2] Baron, J.S., Rueth, H.M., Wolfe, A.M., Nydick, K.R., Allstott, E.J., Minear, J.T. and Moraska, B. (2000) Ecosystem Responses to Nitrogen Deposition in the Colorado Front Range. Ecosystems, 3, 352-368. https://doi.org/10.1007/s100210000032

[3] Benedict, K.B., Day, D., Schwandner, F.M., Kreidenweis, S.M., Schichtel, B., Malm, W.C. and Collett Jr., J.L. (2013) Observations of Atmospheric Reactive Nitrogen Species in Rocky Mountain National Park and across Northern Colorado. Atmospheric Environment, 64, 66-76. https://doi.org/10.1016/j.atmosenv.2012.08.066

[4] Marquardt, W., Buggemann, E., Auel, R., Herrmann, H. and Moller, D. (2001) Trends of Pollution in Rain over East Germany Caused by Changing Emissions. Tellus B. Chemical and Physical Meteorology, 53, 529-541. https://doi.org/10.1034/j.1600-0889.2001.530502.x

[5] Shen, Z., Wong, Z., Zhang, R., Ho, K., Cao, J. and Zhang, M. (2011) Chemical Composition of Water-Soluble Ions and Carbonate Estimation in Spring Aerosol at a Semi-Arid Site of Tongyu, China. Aerosol and Air Quality Research, 10, 360-368. https://doi.org/10.4209/aaqr.2011.02.0010

[6] Durana, N., Casado, H., Ezcurra, A., Garcia, A. and Lacaux, J.P. (1992) Experimental Study of the Scavenging Process by Means of a Sequential Precipitation Collector, Preliminary Results. Atmospheric Environment, 26, 2437-2443. https://doi.org/10.1016/0960-1686(92)90373-S

[7] Cerón, R., Cerón, J., Kahl, J., Lara, R., Rangel, M. and Rustrian, E. (2018) Potential Influence of Emissions and Transport of $\mathrm{N}$ and $\mathrm{S}$ in the Orizaba Valley, Veracruz, Mexico. Agrociencia, 52, 653-670. 
[8] NMX-AA-074-1981. Análisis de aguas. Determinación del ión sulfato en aguas naturales, residuales y residuales tratadas.

[9] Galloway, J.N., Thornton, J.D., Norton, S.A., Volchok, H.L. and McLean, R.A.N. (1982) Trace Metals in Atmospheric Deposition: A Review and Assessment. Atmospheric Environment, 16, 1677-1700. https://doi.org/10.1016/0004-6981(82)90262-1

[10] Ponette-González, A.G., Weathers, K.C. and Curran, L.M. (2010) Tropical Land-Cover Change Alters Biogeochemical Inputs to Ecosystems in a Mexican Montane Landscape. Ecological Applications, 20, 1820-1837. https://doi.org/10.1890/09-1125.1

[11] Parungo, F., Nagamoto, C., Hoyt, S. and Bravo, H.A. (1990) The Investigation of Air Quality and Acid Rain over the Gulf of Mexico. Atmospheric Environment. Part A. General Topics, 24, 109-123. https://doi.org/10.1016/0960-1686(90)90446-T

[12] Cerón, B., Escoffie, R.C., et al. (2015) Spatial and Temporal Distribution of through Fall Deposition of Nitrogen and Sulfur in the Mangrove Forests Associated to Terminos Lagoon. In: Nejadkoorki, F., Ed., Current Air Quality Issues, Intech Open Access Publisher, Rijeka, 147-164. https://doi.org/10.5772/59726

[13] Sosa, R., Bravo, H., Alarcón, A., Torres, M.C., Jaimes, M., Sánchez, P. and Granados, E. (2018) Acid Rain in a Mexian Site on the Coast of the Gulf of Mexico. Atmosfera, 31, 317-330. https://doi.org/10.20937/ATM.2018.31.04.01

[14] Huang, D.Y., Xu, Y.G., Peng, P., Zhang, H.H. and Lan, J.B. (2009) Chemical Composition and Seasonal Variation of Acid Deposition in Guangzhou, South China: Comparison with Precipitation in Other Major Chinese Cities. Environmental Pollution, 157, 35-41. https://doi.org/10.1016/j.envpol.2008.08.001

[15] Cerón, R., Padilla, H., Belmont, R., Torres, M.C., García, R. and Báez, A. (2002) Rainwater Chemical Composition at the End of the Mid-Summer Drought in the Caribbean Shore of the Yucatan Peninsula. Atmospheric Environment, 36, 2367-2374. https://doi.org/10.1016/S1352-2310(02)00169-3

[16] Zhang, M.Y., Wong, S.J., Wu, F.C., Yuan, X.H. and Zhang, Y. (2007) Chemical Composition of Wet Precipitation and Anthropogenic Influences at a Developing Urban Site in Southeastern China. Atmospheric Research, 84, 311-322. https://doi.org/10.1016/j.atmosres.2006.09.003

[17] Draxler, R.R. and Rolph, G.D. (2003) Hysplit (Hybrid Single-Particle Lagrangian Integrated Trajectory) Model.

[18] Kahl, J.D.W., Bravo-Álvarez, H., Sosa-Echeverría, R., Sánchez Álvarez, P., AlarcónJiménez, A.L. and SotoAyala, R. (2007) Characterization of Atmospheric Transport to the El Tajín Archaeological Zone in Veracruz, México. Atmósfera, 20, 359-371. 